\title{
A Case Study of NS and NNS English Teachers Classroom Discourse in an EFL Setting
}

\author{
Shufang Shen \\ X'an Shiyou University, 18th, 2nd Dianzi Road, Xian, Shaanxi Province, P. R. China \\ 13472540@qq.com
}

Keywords: NS English teacher, NNS English teacher, question type, feedback, classroom talk

\begin{abstract}
As English progressively become a Lingua Franca in the globalized world, a rapid increasing number of people begin to learn English, which leads to a growing demand for English education. With assumption that native speakers of English are intrinsically better teachers because their mother tongue is English, more and more school administrators tend to recruit native speakers of English to teach English in ESL/EFL settings. This comparative study adopts classroom observation and the analysis of transcriptions of audio-tape recording, centering on teachers' questions and feedback as well as the effects of teacher questions and teacher feedback on students' oral production between NS English teacher and NNS English teacher to find if NS English teachers are truly effective in teaching English and which teaching mode (NS/ NNS/ team-teaching) benefits students' verbal expression.
\end{abstract}

\section{Introduction}

Nowadays, with the increasingly high frequency of international communication, English, as a Lingua Franca, has become indispensable in international interaction. Consequently, there has been a growing demand for English education. With assumption that native speakers of English are intrinsically better teachers because their mother tongue is English, more and more school administrators tend to recruit native speakers of English to teach English in ESL/EFL settings, especially when communicative approach to language teaching (CLT), which emphasizes more on oral interaction, has been increasingly accepted and implemented in language classroom. However, the majority of teachers of English as foreign or second language are still not native speakers of English. As Canagarajah [1] states, nearly 80 percent of the world's English-language teachers are non-native English speaking teachers (NNESTs). Taking into account of the fact that non-native English speaking teachers (NNESTs) greatly outnumbers native English-speaking teachers (NESTs), a host of research centered on the issue of NNESTs such as self-perception of NNESTs [2] [3], students' perception of NNESTs [4] as well as NNESTs' performance in language classrooms [5]. These studies based on questionnaires, narratives, surveys or interviews demonstrate that NNESTS have their own advantages as well as positive attributes in language teaching. However, the research on comparing the actual teaching performance between NESTs and NNESTs in ESL/ EFL settings is very limited [6]. Thus, this comparative case study examines the differences and similarities between the NS and the NNS English teachers by adopting a micro-analytical approach to teacher's discourse in Chinese EFL setting. "The issue of teacher selection is of special significance in China as the demand of learning English in china is huge" [7].

According to Nunan [8], teacher talk plays the vital role in language class as it is not only the medium by which teachers impart linguistic knowledge but also the primary source of language input. With the advocacy of communicative language teaching and student-centeredness, the study of teachers' discourse in language classroom has mainly focused on teachers' questions [9] [10] and teachers' feedback [11] [12] [13]. Paring NS and NNS English teachers and examining their talk in class, we can find if there are differences or similarities in their verbal behavior as well as its potential consequences on EFL students' learning. Thus, three research questions are formulated: 1 . 
Is there any difference in question types (display questions \& referential questions) initiated by NS English teacher and NNS English teacher? 2. Is there any difference in the way of providing feedback between NS English teacher and NNS English teacher? 3. Is there any difference in the effects of teacher questions and teacher feedback on students' oral production between NS English teacher and NNS English teacher?

\section{Research Methodology}

Given that English classroom has always been the primary and essential channel for EFL learners to be exposed to English, it is worthwhile to investigate the correlation between teachers' talk in classroom and students' language learning. Although there are amount of fruitful studies on teachers' talk in EFL class [9] [10] [11] [12] [13] [14] [15], comparative study on the talk of non-native English speaking teachers and native English-speaking teachers is very rare. This descriptive research was conducted to investigate characteristics of teachers' talk in terms of question types and feedback techniques between NS English teacher and NNS English teacher in a Chinese EFL setting.

\subsection{Research participants}

The participants for present study are one non-native English teacher (NNS teacher) and one native English teacher (NS teacher), who are teaching the oral English course at my home university. The NS teacher is a British man who has more than 16 years' experience of teaching oral English in China and the NNS teacher is a Chinese lady with MA degree in applied linguistics and ten years' teaching experience in teaching college English. In order to control the variables, this research narrows down its scope to the same oral English class with same students taught by both NS and NNS English teachers. Both NS and NNS teachers have the same pedagogical aim: facilitate students to improve their speaking skills. The oral English course is opened for those who are desperate for improving their spoken English and is neither a compulsory course nor elective course. There are altogether 15 students registered in this oral English class but for unknown reasons only 7 students attended the class each time. The students in this class are all non-English major college students who have passed CET 4 (one national standardized exam to test college students' English proficiency) and want to improve their spoken English. Their English proficiencies are intermediate.

\subsection{Research Instrument}

This research aims to find similarities and differences in the features of teachers' discourse in class between NNS and NS English teachers. In order to fulfill the research purpose, this research has adopted the way of natural inquiry, describing and understanding the real process of teaching and learning through observing the natural occurring events in the classroom without any interventions. The instrument used in this research is classroom observation and tape recording. The whole processes of teaching and learning were audio-recorded by a digital recording pen and then the participants' talk was transcribed. There are two reasons for using digital recording pen. For one thing, it is portable and easy to be used in classroom and the use of audio-recorder will avoid the tension and uneasiness caused by video camera thus the participants will maintain their language authenticity. For another, the focus of this study is participants' verbal behavior which can be recorded by audio-tape. Nonetheless, the researcher was always in class to observe what is going on in class, making field notes, which may be helpful in the following transcription and data analysis.

\subsection{Procedure of data collection}

The data in present study began to be collected after IRB application was approved and informed consents from the participants were available. The oral course taught by NS and NNS teacher was scheduled on weekends. Each teacher was audio-recorded twice for two lessons (each lesson lasts 100 minutes). The topics of the lessons taught by NS teacher were music and 
expressions on certainty and uncertainty, whereas the topics of lessons taught by NNS teacher were cultural differences; self-introduction and survival on deserted island; job interview. The total amount for recorded time for each teacher is two hundred minutes. The digital recording pen was placed in the front of the same students' group to record in every lesson.

\subsection{Procedure of data analysis}

When the data had been collected, the transcriptions of the lessons taught by NS teacher and NNS teacher began to be made.

In EFL classroom, teachers' talk not only functions as important language input but also facilitates students' language learning. From the angle of teacher talk as input, the research mainly focuses on teachers' verbal behavior in terms of length of utterances, subordination, vocabulary, grammaticality as well as syntax [19]. However, this present study does not address teachers' talk as input but instead sheds light on teacher-student interaction in English oral class and thus the focus has been placed on the teachers' two most characteristic types of moves: questions and feedback. According to Sinclair and Coulthard (1975), a typical classroom interaction between teacher and students is made up three moves, namely Initiation-Response-Feedback (IRF). Initiation move is usually realized by teachers' questions. Although the taxonomy of teachers' questions is various, this present study adopts the category of questions suggested by Long and Sato [16], display / referential questions because such category relates to the nature of interaction generated [17]. Display questions for which the teacher already knows the answers are usually asked to check if the students know the answer. On the contrary, referential questions for which the teacher does not know the answers are usually asked to elicit students to express their own ideas as well as give the teacher information. As to feedback, since this present study focused more on teacher-student interaction, teachers' feedback narrows to teachers' verbal response towards students' learning performance in class. From this perspective, teachers' feedback can be generally categorized into positive feedback and negative feedback [8]. Positive feedback refers to simple praise or repetition and praise, while according to Lyster \& Mori [18], based on descriptive studies of teacher-student interaction, negative feedback can be categorized into explicit correction, recasts, or prompts. Explicit correction refers to that the teacher gives correct form and clearly states that students' response was wrong. Recast means that the teacher implicitly reformulates what students said. Teachers may use prompts, which include elicitation, metalinguistic clue, clarification requests, or repetition, in order to push students to do self-repair [18].

Based on transcription, teachers' questions were categorized into display questions and referential questions. In addition, teachers' feedback was categorized into positive feedback, which includes simple praise as well as repetition and praise, and negative feedback including explicit correction, recast and prompts. Then simple statistical analysis was adopted to compare the frequency of teachers' different types of questions and different feedback techniques. Finally, a qualitative method was adopted to compare if there is any difference in NS and NNS English teachers' talk in terms of the effectiveness on students' oral production.

\section{Findings and Discussions}

For this oral English course, the NS teacher and the NNS teacher chose different specific topics for students to talk freely. In order to fulfill their teaching aim, both of the teachers have to give students' opportunities to practice the expressions and produce their own utterances. When creating such opportunities, the teachers need to initiate some questions as impetus of starting conversation and also need to provide some feedback after students' utterances to let the interaction move on.

\subsection{Frequency of teachers' different types of questions}

In correspondence with research question one: Is there any difference in question types (display questions \& referential questions) initiated by NS English teacher and NNS English teacher? The simple statistical analysis was made based on the transcriptions of all these four lessons' recordings. 
The data shows that the total number of questions asked by the NS teacher $(n=65)$ surpasses that of questions asked in the NNS teachers' class $(n=52)$. That means that the NS teacher triggered more teacher-student interaction in class as questioning is the common strategy for eliciting information and checking understanding during the whole class teaching [19]. The statistics also shows that in the NS teacher's class, $44.6 \%(n=29)$ are display questions and $55.4 \%(n=36)$ are referential questions; in the NNS teacher's class, $40.4 \%(n=21)$ are display questions and $59.6 \%(n=31)$ are referential questions. This reveals only minimal differences across the NS teacher's class and the NNS teacher's class with respect to percentages of different question types. Brock [20] suggested that referential questions could make students produce longer and syntactically more complex sentences while students' responses would be short, with little elaboration when teachers ask display questions. For the pedagogical aim of this course is to improve students' English speaking, both the NS and the NNS teacher tended to ask more referential questions and less display questions.

\subsection{Distribution of teacher feedback of the NS and the NNS teacher}

In correspondence with research question two: Is there any difference in the way of providing feedback between NS English teacher and NNS English teacher? Based on the transcriptions of all these four lessons' recordings, the simple statistical analysis was made to find out characteristic about distributions of teacher feedback of the NS and the NNS teacher. The data shows that both the NS and the NNS teacher adopted more positive feedback and less negative feedback in the class. Positive feedback is more effective than negative feedback in improving students' learning behavior because positive feedback will not only make students know they have performed correctly, but also increase their learning motivation [8]. However, the NS teacher tended to give more positive feedback which is $61.4 \%(n=43)$ than the NNS teacher gives, which is $56.7 \%(n=38)$. This reveals that the NS teacher gave students more affirmative than the NNS teacher. The students were encouraged to speak out their ideas boldly through teachers' positive feedback. As to negative feedback, a larger proportion of negative feedback occurred in the NNS teacher's class (43.3\%, $\mathrm{n}=29)$ than in the NS teacher's class $(38.6 \%, n=27)$. This manifested that the NNS teacher paid much more attention to language form. Among the three types of negative feedback, the NNS teacher adopted more recast feedback $(72.4 \%, n=21)$ than the NS teacher $(63 \%$, $n=17)$, while frequencies of explicit error correction and prompts in the NS teacher's class are similar to that in the NNS teacher's class.

\subsection{Effects of teacher questions and teacher feedback on students' oral production in the NS and the NNS teacher's class}

In correspondence with research question three: Is there any difference in the effects of teacher questions and teacher feedback on students' oral production between NS English teacher and NNS English teacher? A qualitative discourse analysis was conducted based on transcriptions. In order to effectively examine the effects of teacher talk on students' oral production, the extracts selected to be analyzed are those in which the students produce longer sentences rather than answer yes or no. It can be found that display questions in the both of NS and NNS teachers' class elicited brief and short answers while referential questions prompt students to produce longer and syntactically more complex sentences. Therefore, there is no difference between the effects of question types initiated on students' oral production between the NS and the NNS teachers. However, comparing extract, we see that the NNS teacher asked only one referential question but in the following interaction, the student not only respond to this question but also expand his response to explain the reason of his choice. By contrast, the NS teacher kept asking referential questions in order to constantly prompt students to respond.

As to feedback provided by teachers, although both of the NS and NNS teachers tended to give both positive and negative feedback, there is a difference in the way of providing feedback between the NS teacher and NNS teacher. It can be seen that the NS teacher always provide positive feedback (simple praise) together with negative feedback (recast or prompts) while the NNS teacher 
only gave sole positive feedback or sole negative feedback to students' response at a time. In the NNS teacher's class, the students repeated immediately after the teacher gave correct forms provided in recast. Such kind of students' immediate response to teachers' feedback was defined as uptake by Lyster and Ranta [21]. By contrast, the students' uptake was rare in the NS teacher's class.

As the NNS teacher gave sole negative feedback, it may be easy for students to identify that what they uttered was incorrect in language form. Chinese EFL students have consistently been focused on language form since there is an exam-oriented education system in which accuracy is given as the first priority. It is found in some studies that repetition of teachers' recasts is "a reliable indicator of noticing and a good predictor of learning" [18]. It may be hard for the students to identify whether they need to repair their utterances in the NS teachers' class since the NS teacher mixed simple praise together with recast or prompt. Once the students' got the affirmative from the NS teacher, they may perceive that what they said is right and thus paid less attention to the teacher's follow-up feedback. What's more, the NS teacher focused more on meaningful interaction rather than language form. For instance, when the students gave the answer Michel Jackson, which is not the correct answer the NS teacher expected, the teacher didn't give recast immediately but gave praise first for encouragement of other different responses and then future illustrated that why Michel Jackson is not the expected answer. If the teacher gave recast directly and students repeat after recast, then the interaction may stop and there will not be follow-up teacher-student interaction.

\subsection{Discussions on similarities and differences in teacher questions and feedback between the NS and NNS teachers}

Due to the shared pedagogical goal, to improve students' ability in speaking English, both of the NS and NNS teachers adopted questioning as impetus to start interaction in class. Teachers' questions "provide necessary stepping stones" to classroom interaction in second language classroom. However, the NS teacher seems to ask more questions to prompt students' speaking. In Chinese culture, face is valued highly. When interacting with native speaker, the Chinese EFL students usually feel uneasy and are afraid of being laughed by native speaker since their English proficiency is much lower than native speaker and they would prefer to be a listener rather than a speaker in the interaction. To encourage students to speak, the NS teacher had to ask more questions in order to push the students to utter words. Apart from questioning strategy to prompt students' utterances, the NS teacher also adopted simple praise more often than the NS teacher. Consistent simple praise from the NS teacher would help students build their confidence to speak English and thus they would like to express their opinions boldly. However, in the NNS teacher's class, it is not very necessary to ask questions to elicit students' response because the students expressed their ideas more spontaneously. This may be attributed to that the students would be allowed to speak Chinese if they could not express their ideas appropriately in English in the NNS teacher's class.

Both of the NS and NNS teachers give more positive and less negative feedback to students' responses.Learners' language proficiency and nature of learning tasks are two crucial factors to impact teachers' way of providing feedback. In oral English class, the learning task for students is to engage in real communication. Therefore, both the NS and NNS teachers provide more positive feedback in order to make the interaction go on. Compared to students' rare repetition after the NS teacher's recast, the NNS teacher's recast elicit students' immediate repetition. In the NS teacher's class, the focus of the teacher is not on language form but meaningful interaction. Although the NS teacher gave recast as well, a simple praise usually was given together with recast. The students could not only be engaged into meaningful interaction but also build their self-confidence in English speaking. However, in the NNS teacher's oral class, both the NNS teacher's and students' focus is consistently on the language itself, which resulted in that whenever the teacher gave recast, the students immediately repeated. Simple repetition might not contribute to second language development since the repair is initiated and completed by the teacher within a single move [18]. If the students' focus keeps on language form rather than meaning, it would be hard to improve their 
speaking skills since real communication emphasizes more on meaningful exchange.

\section{Conclusion}

Due to the limited time to collect data, the data source is not multiple. This study would be more reliable if multiple data sources are used, for instance, apart from the classroom observation and audio-tape recording, implementing questionnaire to investigate students' attitudes to the NS and NNS teacher in terms of questions they asked and feedback they provided, and interviewing the NS and NNS teachers to investigate their implicit principles of adopting particular questions or feedback. However, from the classroom observation and the analysis of transcriptions of audio-tape recording, we really find some similarities and differences in teachers' discourse between the NS and NNS teachers. They both tend to ask referential questions in order to elicit students' longer utterances and they both give students more positive feedback to encourage them to go on with the interaction. The NS teacher tended to ask more questions to consistently push the students to speak English. Various questions asked by the NS teacher are also important language input, which may facilitate students' language learning. The NNS teacher focused more on language form. Through providing recast clearly, the NS teacher helped students' uptake of correct language form. However, by giving praise first then followed by recast or prompts, the NS teacher focused more on meaningful interaction. The students may not only improve their confidence in speaking English but more importantly they will raise their awareness that meaning is given as the first priority in communication. In this oral English course which is co-taught by the NS and NNS teachers, the students can not only get more opportunities to practice their English speaking but they can focus on different aspects of language, such as correct language form or meaningful interaction in different teacher's class. The result of the study manifested that team-teaching of classes with NS and NNS teachers would benefit more to students' language learning.

\section{References}

[1] Canagarajah , A. S. (1999). Interrogating the 'native speaker fallacy': Non-linguistic roots, non pedagogical results. In Braine, G. (Ed.), Nonnative educators in English language teaching (pp. 77-92). Mahwah, NJ: Lawrence Erlbaum.

[2] Medgyes, P. (1994). The non-native teacher. London: Macmillan. Ismaning: Max Hueber Verlag.

[3] Tang, C. (1997). On the power and status of non-native ESL teachers. TESOL Quarterly 31 (3), 577-580.

[4] Lasagabaster, D. \& J. M. Sierra (2005). What do student think about the pros and cons of having a native speaker teacher? In Llurda, E, (Ed.), Non-native language teachers: Perceptions, challenges, and contributions to the profession (pp. 217-242). New York: Springer.

[5] Cook, V. J. (2001). Using the first language in the classroom. Canadian Modern Language Review, 57 (3), 402-423.

[6] Árva, V. \& Medgyes, P. (2000). Native and non-native teachers in the classroom. System, 28, 355-372.

[7] He, Deyuan \& Miller, L. (2011). English teacher preference: the case of China's non-English-major students. World Englishes, 30 (3), 428-433.

[8] Nunan, D. (1991). Language Teaching Methodology: A textbook for teachers. Englewood Cliffs, NJ: Prentice Hall.

[9] Nunn, R. (1999). The purposes of language teachers’ questions. IRAL, 37(1), 23-42. 
[10] Ho, D. G. E. (2005). Why do teachers ask the questions they ask? Regional Language Centre Journal, 36(3), 297-310.

[11] Cullen, R. (2002). Supportive teacher talk: the importance of the F-move. ELT Journal, 56 (2), 117-127.

[12] Smith, H., \& Higgins, S. (2006). Opening classroom interaction: The importance of feedback. Cambridge Journal of Education, 36(4), 485-502.

[13] Seedhouse, P. (2004). The interactional architecture of the language classroom: A conversation analysis perspective. Malden, MA: Blackwell.

[14] Burns, C., \& Myhill, D. (2004). Interactive or inactive? A consideration of the nature of interaction in whole class teaching. Cambridge Journal of Education, 34(1), 35-49.

[15] Waring \& Zhang (2008). Using Explicit Positive Assessment in the Language Classroom: IRF, Feedback, and Learning Opportunities. The Modern Language Journal 92, 577-594.

[16] Long, M. \& Sato, C. (1983). Classroom foreigner talk discourse: Forms and functions of teachers' questions. In H. W. Selinger \& M. H. Long (Eds.), Classroom-oriented research in second language acquisition (pp. 268-286). Rowley: Newbury.

[17] Tsui, A. B. M. (1995). Introducing classroom interaction. London: Penguin English

[18] Lyster, R. \& Mori, H. (2006). Interactional feedback and instructional counterbalance. Studies in Second Language Acquisition, 28 (2), 269-300.

[19] Yang, C. C. R. (2010). Teacher questions in second language classrooms: an investigation of three case studies. Asian EFL Journal, 12 (1), 181-201.

[20] Brock, C. A. (1986). The effects of referential questions on ESL classroom discourse. TESOL Quarterly, 20 (1), 47-59.

[21] Lyster, R., \& Ranta, L. (1997). Corrective feedback and learner uptake. Studies in Second Language Acuqisition, 19, 37-66. 